Research Article

\title{
Experimental Study on Seismic Response of Buried Oil and Gas Pipeline Soil Layers under Lateral Multipoint Excitation
}

\author{
Jianbo Dai $\mathbb{D},{ }^{1}$ Li Wang $\left(\mathbb{D},{ }^{2}\right.$ Chengtao $\mathrm{Hu}\left(\mathbb{D},{ }^{1}\right.$ and Guidi Zhang $\mathbb{D}^{1}$ \\ ${ }^{1}$ Xi'an Shiyou University, Xi'an 710065, China \\ ${ }^{2}$ Shaanxi Zhongli Testing and Identification Co., Ltd., Xi'an 710077, China \\ Correspondence should be addressed to Jianbo Dai; 184298843@qq.com
}

Received 7 May 2021; Accepted 1 July 2021; Published 10 July 2021

Academic Editor: Honglue Qu

Copyright (c) 2021 Jianbo Dai et al. This is an open access article distributed under the Creative Commons Attribution License, which permits unrestricted use, distribution, and reproduction in any medium, provided the original work is properly cited.

The seismic response of buried oil and gas pipelines is mainly influenced by the site soil. In this paper, a bidirectional laminar shear continuum model box is developed for the site response of buried oil and gas pipelines under transverse multipoint seismic excitation. By comparing the acceleration response of the soil and pipeline, monitoring the soil displacement, and analyzing the acceleration coefficient and Fourier spectrum, the seismic response characteristics of the soil at different excitation modes and peak seismic acceleration and its laws were investigated. The test results show that the soil under transverse excitation undergoes the process of soil compaction to nonlinear characteristics and finally soil damage, and the course of multipoint excitation develops faster and causes more serious soil damage. The peak Fourier spectrum of both the pipe and the soil appears at the frequency of $4-6 \mathrm{~Hz}$, and in general, the acceleration of the pipe is greater than that of the soil; the difference between the two gradually decreases with the increase of loading level. Compared with the uniform excitation, the increase in the loading level during the lateral multipoint excitation will result in a decrease of the consistency of the acceleration time history curve at each measurement point and a decrease of the peak of the spectrum. The effect of laminar shear between soil bodies becomes more obvious with the increase of acceleration peaks on the shaking table. It is also found out that the excitation method has little effect on the displacement time history curve, but the multipoint excitation may cause fluctuations in the displacement time history curve.

\section{Introduction}

With the gradual improvement of oil and gas transportation pipeline networks, the local failure of oil and gas transportation pipeline networks caused by earthquakes often results in huge wealth losses. Due to factors such as length routs, multiple and complex geological conditions, and strong uncertainty of earthquakes, the seismic performance of pipelines has been a popular issue by various scholars [1]. Numerous studies have shown that the seismic response of buried oil and gas pipelines is mainly influenced by the vibration of the surrounding soil [2]; therefore, exploring the nonlinear seismic response of the site around buried pipelines is an effective way to study and analyze the design of pipeline seismic damage prevention and control.
Site response under seismic action is the basis for analyzing the seismic response of underground structures $[3,4]$. Haydar and Bilge [5] and Yang and Yan [6] investigated the effect of nonlinear properties of soil on-site response and analyzed the influencing factors. Angshuma and Pradipta [7] studied the local effects of the site using nonlinear one-dimensional numerical analysis. Alireza et al. [8] evaluated four known nonlinear equivalence methods based on the seismic design of a subway tunnel in Tehran. Rashidov et al. [9] and Delong et al. [10] carried out numerical simulations of buried pipe-soil interactions to explore the changes in mechanical properties between pipes and soils during seismic action.

In conjunction with studies related to soil nonlinear response, Subramanian et al. [11], Yong et al. [12], and Ouyang et al. [13] carried out shaking table tests for long 
tunnels and underground galleries under multipoint excitation to analyze the nonlinear characteristics of the soil around the structures, respectively. Junyan et al. [14] and Yan et al. [15] conducted shaking table tests for underground structures under nonuniform excitation separately in order to analyze the influence of soil type and burial depth of the underground structures on the structural response. They found out that the type of soil and the burial depth of the underground structure had a greater influence on the structural response, and the dynamic response of the site under multipoint excitation was more in line with the actual response during earthquakes than under uniform excitation. Buried pipes are redundant structures with axial dimensions much larger than their radial dimensions, causing different seismic waves to form at different points during earthquake propagation, rather than just a lag in the arrival time of the seismic waves. George et al. [16] conducted research and analysis on a multipoint seismic wave synthesis, providing a method for multipoint seismic wave input in shaking table tests.

Based on the above research, this paper designs a bidirectional laminated shear continuum model box, synthesizes three sets of coherent waves with different vibration waveforms as the input waves of two shakers based on seismic wave synthesis theory, conducts shaking table array tests of buried oil and gas pipelines under transverse multipoint seismic excitation, analyzes the seismic response law of the soil around buried oil and gas pipelines under different ground vibrations, different peak seismic accelerations, and different excitation methods, and provides a reference for subsequent simulation analysis and pipeline design.

\section{Experimental Investigation}

2.1. Simulate Relationship and Test Material. The test is a scaled-down model test, with the complete model for the pipe and the ignored gravity model for the soil. Considering the limitations of the test site conditions, a similarity ratio design was carried out for the length $(l)$, modulus of elasticity $(E)$, density $(\rho)$, stress $(\sigma)$, strain $(\varepsilon)$, acceleration $(a)$, and gravitational acceleration $(g)$ of the model based on the similarity ratio principle and volume analysis [17], and the obtained material similarities are as shown in Table 1.

The cross-sectional size of the prototype pipe was $1422 \mathrm{~mm} \times 33.3 \mathrm{~mm}$. Combining the dimensions of the model box used and the similar ratio design, it was determined that the pipe was made of L245 type longitudinal resistance welded steel pipe with a cross-sectional size of $14 \mathrm{~mm} \times 3.0 \mathrm{~mm}$ and a length of $3500 \mathrm{~mm}$, and the internal pressure was $8 \mathrm{MPa}$. The specific parameters of the pipe material are shown in Table 2. The soil used in the test is saturated sand with a density of $1.78 \mathrm{~g} / \mathrm{cm}^{3}$, the corresponding moisture content is $14.1 \%$, the internal friction angle is $28.5^{\circ}$, and the cohesion is $10.6 \mathrm{kPa}$.
TABLe 1: Simulate relationship.

\begin{tabular}{lcccccccc}
\hline Material & $S_{l}$ & $S_{E}$ & $S_{\rho}$ & $S_{\sigma}$ & $S_{\varepsilon}$ & $S_{f}$ & $S_{\alpha}$ & $S_{g}$ \\
\hline Pipeline & $1 / 10$ & $1 / 10$ & 1 & $1 / 10$ & 1 & 3.16 & 1 & 1 \\
Soil & $1 / 10$ & $1 / 4$ & 1 & $1 / 4$ & 1 & 5 & 2.5 & 1 \\
\hline
\end{tabular}

\subsection{Bidirectional Laminar Shear Continuum Model Box.}

The test was carried out on a shaking table at the Hunan Provincial Key Laboratory of Structural Vibration and Wind Resistance, with two shaking tables of $1000 \mathrm{~mm} \times 1000 \mathrm{~mm}$ in size and spacing of $2000 \mathrm{~mm}$ between the two adjacent shakers. The shaking table uses a three-parameter servo control system to control the acceleration of the input table, which enables bi-directional four degrees of freedom loading, with a maximum speed of $\pm 400 \mathrm{~mm} / \mathrm{s}$ in the horizontal direction and a maximum displacement of \pm $75 \mathrm{~mm}$ in the horizontal direction.

For this test, a bidirectional laminated shear continuum model box [18] was developed, with an outer diameter of $4160 \mathrm{~mm} \times 840 \mathrm{~mm} \times 940 \mathrm{~mm}$ and an inner diameter of $3900 \mathrm{~mm} \times 600 \mathrm{~mm} \times 800 \mathrm{~mm}$. The box is divided into three main sections: each section is connected by an articulated extension device and the left and right sections are placed on the table, with the two ends of the middle section resting on the edge of the table to bear the weight of the middle section. The box is made up of nine layers of independent frames stacked together along the height direction; each layer of the frames is provided with grooves and built-in balls to connect them, to ensure that horizontal laminar shearing can occur during vibration. To prevent excessive deformation of the box when the table surface increases in acceleration, limit plates are provided on each frame layer on both sides of the box and limit ropes are also provided in the middle section of the box. The soil is loaded into the box in four layers, after each layer of soil is loaded, compaction is then carried out and sensors or pipes are buried. The final site layout and model is shown in Figure 1.

2.3. Measurement Point Arrangement. To study the seismic response of the soil from top to bottom during the test loading process, three monitoring surfaces were arranged along the length of the box, and three groups of sensors were placed along with the height of the soil in each monitoring surface, with the height of each sensor being $150 \mathrm{~mm}, 360 \mathrm{~mm}$, and $650 \mathrm{~mm}$, respectively. The acceleration measurement points are M11-M33 and displacement sensors are D11-D33. The measurement points on the pipe (A1-A5) are equipped with three-way acceleration sensors at $750 \mathrm{~mm}$ intervals from $250 \mathrm{~mm}$ from the end of the pipe to monitor the acceleration changes of the pipeline. The layout of the soil acceleration sensors and displacement meters and pipeline acceleration sensors is shown in Figure 2. 
TABLE 2: Mechanical properties of the pipeline.

\begin{tabular}{lccccc}
\hline Material & Diameter $(\mathrm{mm})$ & Thickness $(\mathrm{mm})$ & Yield strength $(\mathrm{MPa})$ & Tensile strength $(\mathrm{MPa})$ & Internal pressurization $(\mathrm{MPa})$ \\
\hline L245 & 140 & 3 & 245 & 415 & 8 \\
\hline
\end{tabular}

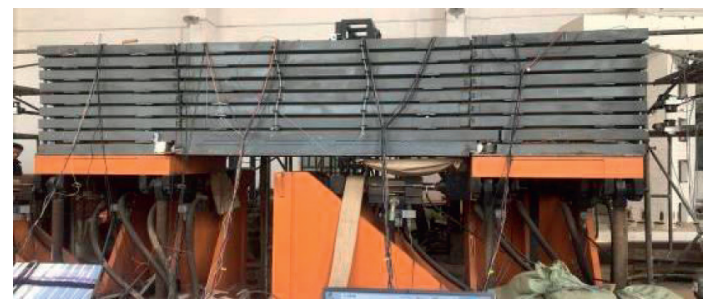

(a)

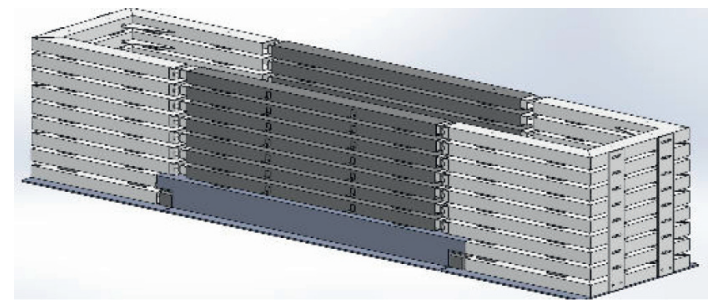

(b)

Figure 1: Design of the test model box. (a) Site layout of the model box. (b) Design of the model box.

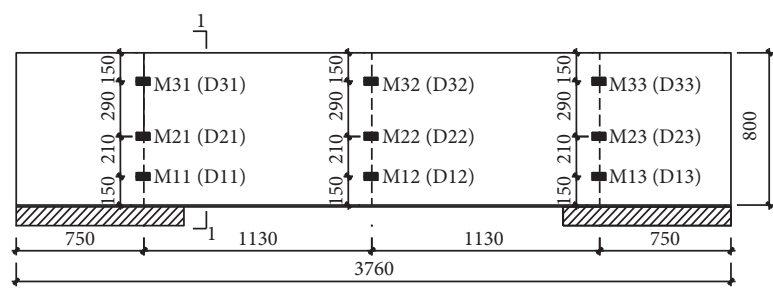

(a)

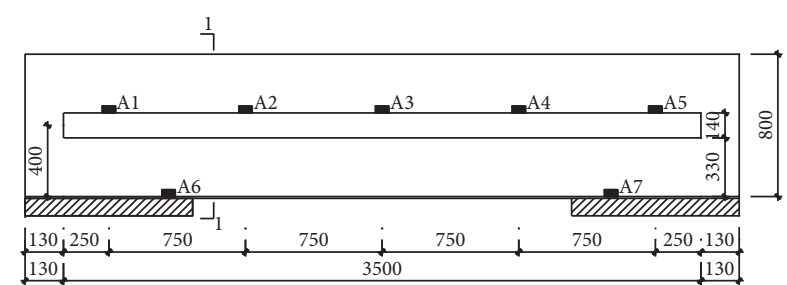

(b)

Figure 2: Layout of measuring point. (a) Layout of acceleration and displacement sensors in soil. (b) Layout of acceleration sensors in the pipeline.

2.4. Seismic Wave Selection and Test Conditions. The ELCentro wave (E wave) and Wenchuan wave (W wave) were chosen as the original seismic waves in the experiment. Based on the multipoint seismic wave synthesis theory, the reciprocal power spectrum model was applied and the coherence between the two points was used to make corrections in the original seismic waves based on the coherent amplitude and coherent phase angle. This results in a time course of seismic waves at two different locations considering spatial correlation.

The experiment uses artificial randomly synthesized multipoint seismic waves (R-wave) as an approximate transformation relationship based on the response spectrum and power spectrum and generates a mutual power spectrum matrix using the coherence function to form the total power spectrum matrix. The power spectrum matrix is used to generate the Fourier amplitude spectrum at each point, and a fast Fourier transform is performed from the amplitude and phase spectra to obtain the smooth acceleration time course at each point. The smooth time course is then multiplied by the intensity envelope function to obtain the ground shaking time course that satisfies the time-frequency nonsmoothness. Finally, the final acceleration timescale is output by long-period filtering and baseline adjustment. The synthesis of the two multipoint excitation seismic waves was programmed using MATLAB software, and after similar ratio conversion and peak adjustment, seismic waves with acceleration peaks of $0.25 \mathrm{~g}, 0.5 \mathrm{~g}, 1.0 \mathrm{~g}$, and $1.55 \mathrm{~g}$ were input to the loading table to simulate 7 degrees', 8 degrees', 9 degrees', and 9 degrees' rare earthquakes, respectively. Figure 3 shows the time course curves of the three multipoint excitation seismic waves with adjusted acceleration peak of $0.25 \mathrm{~g}$.

The two coherent waves were used as input waves for the two shaking tables for multipoint input, while the same seismic waves converted by similarity ratio were input directly at both tables at the same time for uniform input, and the tables were input in the order of gradually increasing amplitude from $0.25 \mathrm{~g}$ to $1.55 \mathrm{~g}$ to analyze the damage pattern and seismic response of the model at different acceleration peaks. The specific loading conditions are shown in Table 3.

\section{Test Results and Analysis}

3.1. Experimental Macroscopic Reaction Phenomena. By comparing the macroscopic response of the soil layer during the uniform and multipoint excitation, it was found that the variation of the model soil box was small for the input table peak acceleration of $0.25 \mathrm{~g}$ and $0.50 \mathrm{~g}$ under lateral uniform excitation and the soil and box were in a stable vibration state. There was no obvious change on the surface of soil at this time. At the third stage of loading $(1.00 \mathrm{~g})$, the movement of the soil box increased, and both top and bottom of 


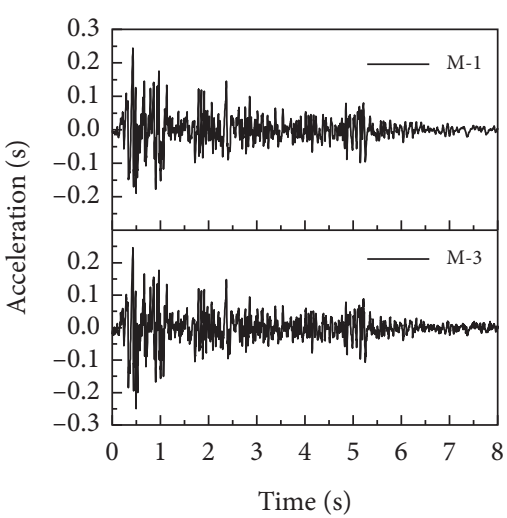

(a)

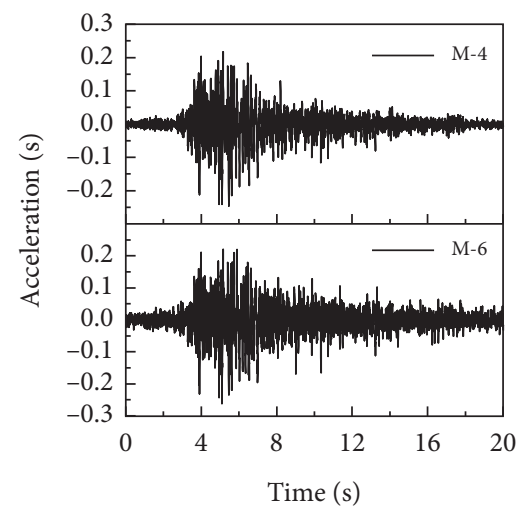

(b)

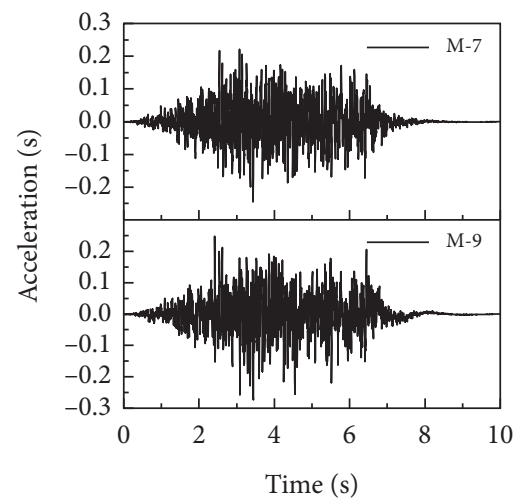

(c)

FIgUre 3: Multipoint seismic wave of the platform. (a) EL-Centro waves. (b) Wenchuan waves. (c) Artificial waves.

TABLE 3: Working condition of the test.

\begin{tabular}{|c|c|c|c|c|c|c|c|c|}
\hline \multirow{2}{*}{ Working condition } & \multicolumn{3}{|c|}{ Uniform excitation } & \multirow{2}{*}{ Working condition } & \multicolumn{3}{|c|}{ Multipoint excitation } & \multirow{2}{*}{ Remarks } \\
\hline & Amplitude (g) & Table 1 & Table 2 & & Amplitude (g) & Table 1 & Table 2 & \\
\hline 1 & 0.25 & M-1 & M-1 & 2 & 0.25 & M-1 & M-3 & \\
\hline 3 & 0.25 & M-4 & M-4 & 4 & 0.25 & M-4 & M-6 & 7 degrees \\
\hline 5 & 0.25 & M-7 & M-7 & 6 & 0.25 & M-7 & M-9 & \\
\hline 7 & 0.50 & $M-10$ & M-10 & 8 & 0.50 & M-10 & M-12 & \\
\hline 9 & 0.50 & M-13 & M-13 & 10 & 0.50 & M-13 & M-15 & 8 degrees \\
\hline 11 & 0.50 & M-16 & M-16 & 12 & 0.50 & M-16 & M-18 & \\
\hline 13 & 1.00 & M-28 & M-28 & 14 & 1.00 & M-28 & M-30 & \\
\hline 15 & 1.00 & M-31 & M-31 & 16 & 1.00 & M-31 & M-33 & 9 degrees \\
\hline 17 & 1.00 & M-34 & M-34 & 18 & 1.00 & M-34 & M-36 & \\
\hline 19 & 1.55 & M-37 & M-37 & 20 & 1.55 & M-37 & M-39 & \\
\hline 21 & 1.55 & M-40 & M-40 & 22 & 1.55 & M-40 & M-42 & 9.5 degrees \\
\hline 23 & 1.55 & M-43 & M-43 & 24 & 1.55 & M-43 & M-45 & \\
\hline
\end{tabular}

the box began to exhibit large displacement, while the displacement of the central soil body was relatively small due to the constraints of the oil and gas pipeline, at which time the soil cracks appeared and gradually propagated in all directions. At the final stage of loading $(1.55 \mathrm{~g})$, the soil gradually loosened due to large shear deformation, and the nonlinear characteristics of the soil gradually became obvious. With the continuous application of the load, local subsidence occurred at the end of the soil box and the soil was damaged.

The macroscopic response phenomena under lateral multipoint seismic excitation are similar to those under uniform excitation. However, the soil deformation under multipoint excitation is significantly larger compared with uniform excitation when the peak acceleration of the table is less than $0.50 \mathrm{~g}$, and fine cracks begin to appear on the surface of the soil. When the peak acceleration of the table is $1.00 \mathrm{~g}$, the soil box has a serpentine motion of each layer of the frame, and the inconsistent motion of each layer of the frame leads to large shear deformation of the soil, and the soil starts to show nonlinear characteristics. When the peak acceleration of the table reaches $1.55 \mathrm{~g}$, the movement of the soil box is huge, and the upper limit bolts of each layer of the soil box frame collide with the limit plate, making a large sound, and the soil body is seriously damaged. The final damage state of the soil body is shown in Figure 4.

Comparing the macroscopic response phenomena of the soil box and soil under uniform and multipoint excitation, the macroscopic response phenomena observed under different excitation methods are similar, but the deformation of the soil box and soil is relatively more obvious during multipoint excitation. The deformation of the soil box and the soil is relatively obvious during the multipoint excitation. During the first two levels of loading, the deformation of the two boxes is the same and the soil body is in the compaction process, but as the loading level increases, the overall deformation of the model produced by the multipoint excitation is greater than that of the unanimous excitation.

3.2. Time Course Analysis of the Pipe and Surrounding Soil Acceleration. In order to analyze the acceleration response of the pipe and the surrounding soil, the seismic response of the Wenchuan wave was used as the research object, and the acceleration time curves and Fourier spectra of the pipe and the soil at the peak acceleration of $0.25 \mathrm{~g}$ and $1.55 \mathrm{~g}$ on the table were extracted for comparison. The acceleration time curve and Fourier spectrum are shown in Figures 5 and 6. 


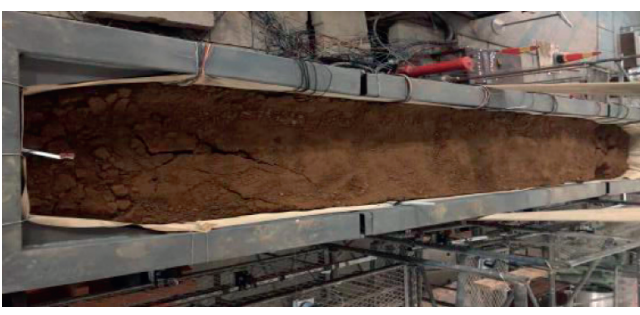

(a)

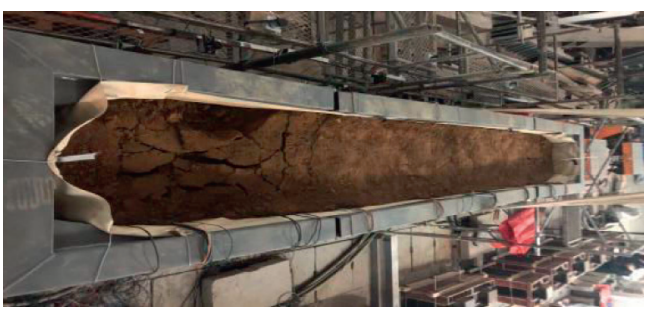

(b)

Figure 4: Final failure state of soil. (a) Left side. (b) Right side.
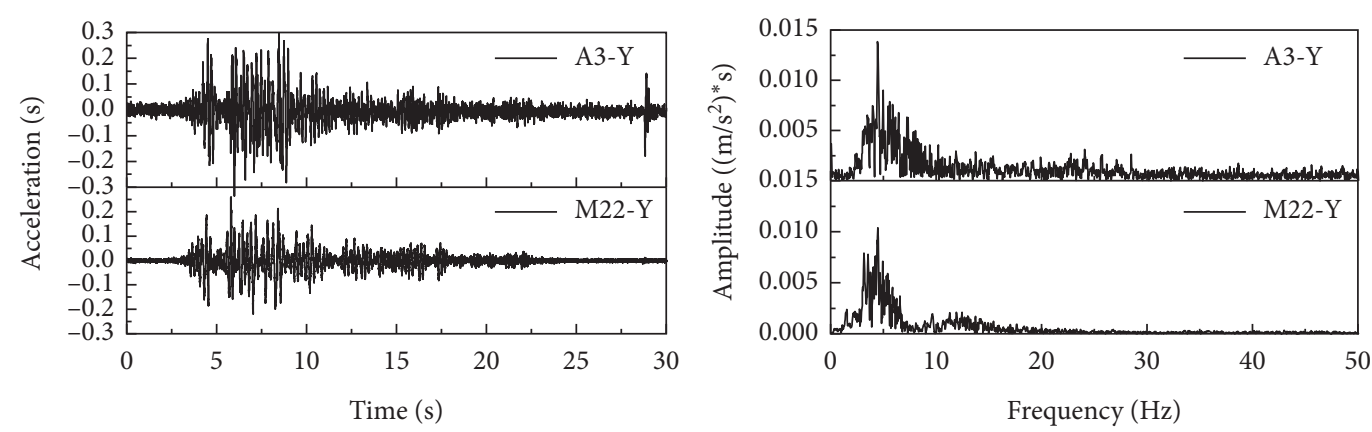

(a)
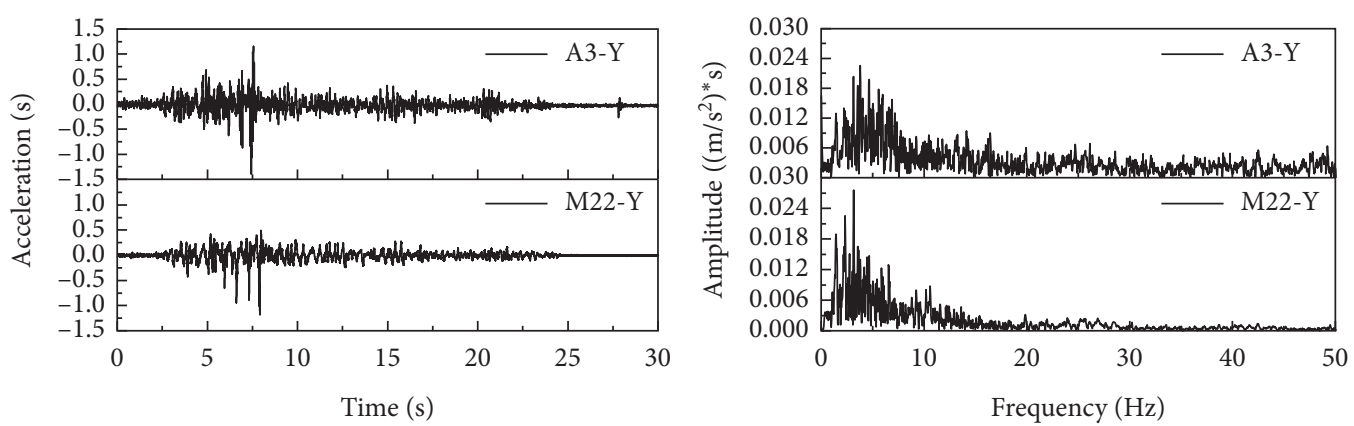

(b)

FIgURE 5: Acceleration time history and Fourier spectrum of pipeline and soil under uniform excitation. (a) $0.25 \mathrm{~g}$. (b) $1.55 \mathrm{~g}$.

Figure 5 shows the acceleration time response curves and Fourier spectra of the pipe and the soil for the table acceleration peaks of $0.25 \mathrm{~g}$ and $1.55 \mathrm{~g}$ under uniform lateral excitation. The peak acceleration of the pipe is slightly greater than the peak acceleration of the soil, at which time the soil in the soil box is in a compacted state, and the pipe moves in concert with the surrounding soil. The Fourier spectra of the pipe and the soil are the same, but the peak point composition of the pipe spectrum is richer than that of the soil. When the peak acceleration of the platform is $1.55 \mathrm{~g}$, due to the large deformation of the soil box and the soil, the shear deformation of the soil is serious. The pipe and soil acceleration time curve is more different and the soil has many peak points while the peak points in the pipe appear in the $6 \sim 8 \mathrm{~s}$. The peak acceleration of the pipe is about 1.2 times that for the soil. The peak of the Fourier spectrum is slightly smaller than that of the soil.

Figure 6 shows the acceleration time response curves and Fourier spectra of the pipe and the soil for the table acceleration peaks of $0.25 \mathrm{~g}$ and $1.55 \mathrm{~g}$ under multipoint excitation. At the first stage $(0.25 \mathrm{~g})$, there is a difference between the acceleration time curves of the pipe and the soil, with multiple peak points in the pipe acceleration, and the peak is significantly larger than the peak of the soil acceleration. At the fourth-stage $(1.55 \mathrm{~g})$ loading, the vibration frequency and acceleration peak of the pipe are still relatively large, and the peak size of the Fourier spectrum of the pipe and the soil changes, with the peak point of the soil spectrum exceeding that of the pipe gradually. The reason for this is that at the last stage of loading the soil is loose and the mutual restraint between soil and pipe is weakened, and the pipe is basically in a free vibration state while the soil vibration is still restrained by the acceleration of the table.

Comparing the acceleration response of the pipe and soil at uniform and multipoint excitation, it can be concluded that the pipe acceleration is greater than the soil acceleration at all levels of loading, and this gradually decreases as the peak acceleration of the input table increases. The Fourier 

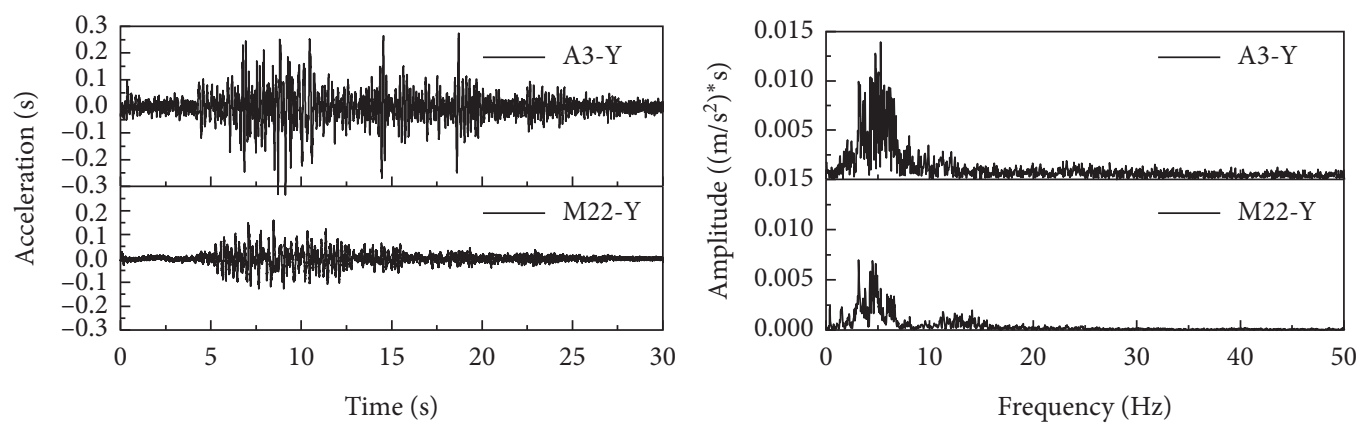

(a)
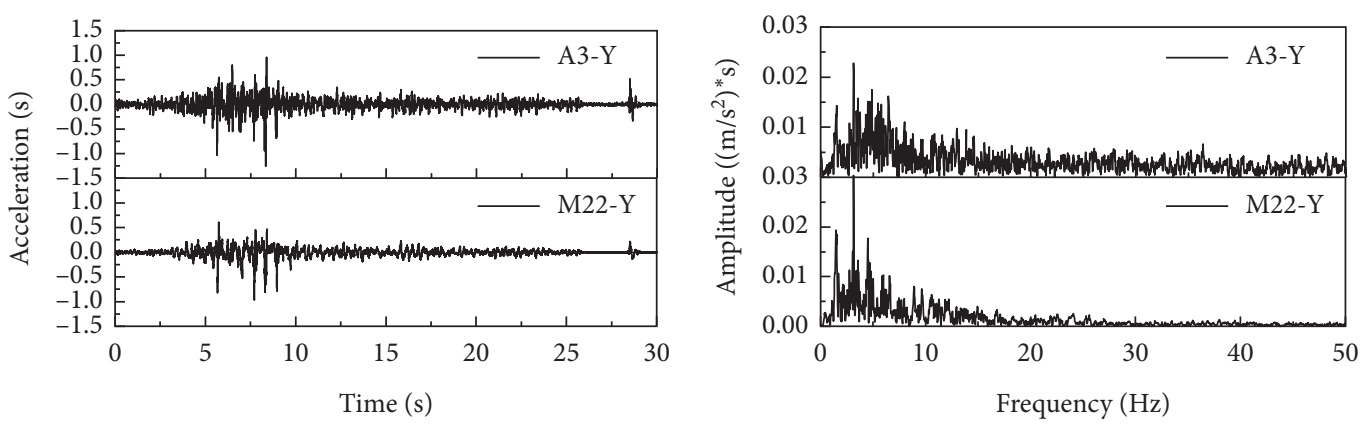

(b)

FIGURE 6: Acceleration time history and Fourier spectrum of pipeline and soil under multipoint excitation. (a) $0.25 \mathrm{~g}$. (b) $1.55 \mathrm{~g}$.

spectrum of the pipe is richer than that of the soil, with the peak of the pipe spectrum larger than that of the soil when the peak acceleration of the table is small. As the table becomes large, the peak of the soil spectrum gradually increases and exceeds that of the pipe.

3.3. Acceleration Amplification Factor. The study shows that the presence of buried pipes affects the seismic response state of the soil around the pipes. The variation curve of the soil acceleration amplification coefficient of the model soil box when extracting different ground shaking effects is shown in Figures 7 and 8 . It can be found that the peak acceleration of the soil with the height of the measurement point shows a tendency to decrease initially and then increase.

Under the uniform excitation, the acceleration amplification coefficients at the bottom measurement points are all around 1 at the first stage of loading. When the height of the measured points increases, the peak acceleration of both $\mathrm{E}$ and $\mathrm{W}$ waves increases. And the peak acceleration of the soil exceeds that of the table, which is up to 1.26 times the peak acceleration of the table, while the $\mathrm{R}$ wave only produces acceleration amplification at the surface of the soil. As the peak acceleration of the table increases, the soil acceleration amplification curve shrinks more significantly at the elevation of the pipe, and the acceleration amplification factor generated by the soil in the box is less than 1 at this time.

The acceleration trends of the soil under different ground vibrations are the same for multipoints excitation. At the first stage of loading, the $\mathrm{W}$ and $\mathrm{R}$ wave amplification coefficients were similar, both of them converged at the measurement point where the pipe was laid, the amplification effect of the soil at the bottom and middle of the table under the action of $\mathrm{E}$ wave was not obvious, and the acceleration amplification coefficient at the top measurement point was larger due to the loose soil, reaching 1.35. With the increase of the loading level, the acceleration amplification coefficient of the soil decreased compared with the first stage of loading, and the contraction of each measurement point was obvious at the height of $360 \mathrm{~mm}$. The reason for this is that the multipoint excitation causes the two ends of the pipe to vibrate in different directions and with different amplitudes, resulting in greater disturbance of the soil by the pipe and significant changes in the peak acceleration of the soil.

Both the difference in excitation method and type of earthquake and loading level have important effects on the change of acceleration amplification coefficient of the soil. At the same loading level, the acceleration amplification coefficients at each measurement point shrink more significantly at the pipe elevation, indicating that the shear deformation of the soil is greater and more likely to enter the nonlinear development phase. At the same time, the values of acceleration amplification coefficients and their reduction at the central measurement point are significantly greater than at the remaining measurement points, indicating that the burial of the pipe causes the acceleration amplification coefficients of the surrounding soil to contract significantly.

3.4. The Impact of Buried Pipelines on the Seismic Response of the Site. In order to further analyze the trend of soil acceleration with the height of the measurement points, the acceleration time courses of acceleration measurement point 


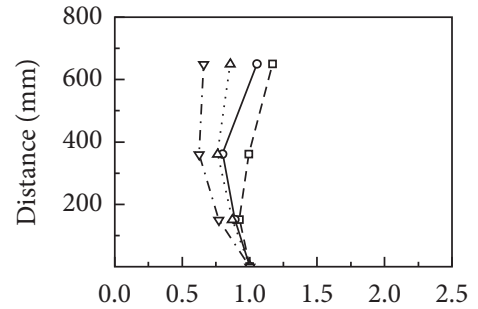

Acceleration amplification coefficient

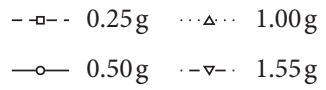

(a)

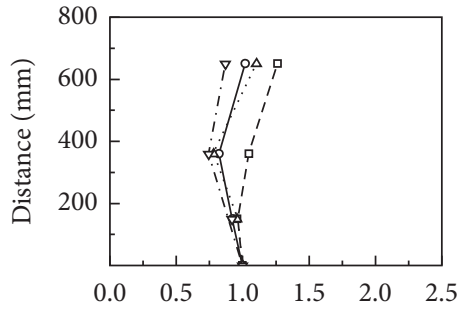

Acceleration amplification coefficient

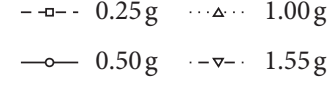

(b)

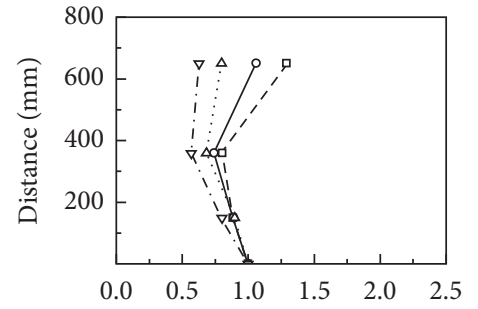

Acceleration amplification coefficient

$\begin{array}{llll}-\square--0.25 g & \cdots \Delta \cdot 1.00 \mathrm{~g}\end{array}$

(c)

Figure 7: Uniform excitation. (a) EL-Centro waves. (b) Wenchuan waves. (c) Artificial waves.

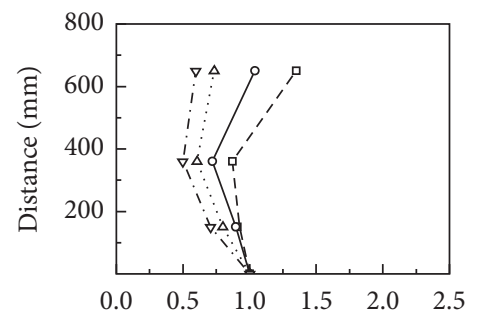

Acceleration amplification coefficient

$$
\begin{array}{cccc}
-\square-- & 0.25 \mathrm{~g} & \cdots \Delta \cdot & 1.00 \mathrm{~g} \\
\hdashline-0.50 \mathrm{~g} & -\nabla-\cdot 1.55 \mathrm{~g}
\end{array}
$$

(a)

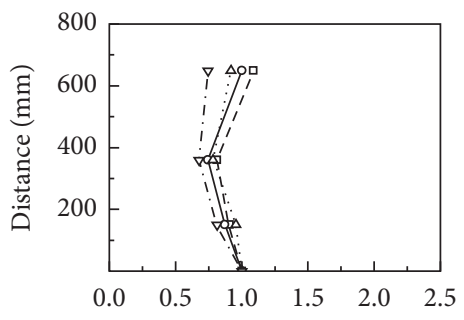

Acceleration amplification coefficient

$$
\begin{array}{cccc}
-\multimap-- & 0.25 \mathrm{~g} & \cdots \Delta \cdots & 1.00 \mathrm{~g} \\
\hdashline-0.50 \mathrm{~g} & -\nabla-\cdot & 1.55 \mathrm{~g}
\end{array}
$$

(b)

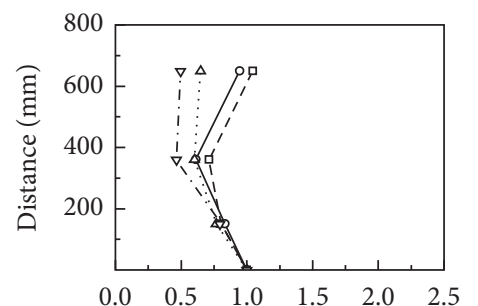

Acceleration amplification coefficient

$$
\begin{array}{cccc}
-\square-- & 0.25 \mathrm{~g} & \cdots \Delta \cdot \cdots & 1.00 \mathrm{~g} \\
\multimap & 0.50 \mathrm{~g} & \cdot-\nabla-\cdot & 1.55 \mathrm{~g}
\end{array}
$$

(c)

FIgURE 8: Multipoint excitation. (a) EL-Centro waves. (b) Wenchuan waves. (c) Artificial waves.

M11, M21, and M31 were extracted for analysis at uniform and multipoint excitation. Due to the length restrictions of the paper, the authors selected the soil acceleration variation data under the action of $\mathrm{W}$ wave for processing and obtained the soil acceleration time course curve and its Fourier spectrum at $0.25 \mathrm{~g}$ and $1.55 \mathrm{~g}$ loading as shown in Figures 9 and 10 .

Figure 9 shows the acceleration time curve and its Fourier spectrum of each measuring point for different loading levels under uniform lateral excitation. It is obvious that the waveforms of the acceleration time course curves at different height measurement points are similar when the first level $(0.25 \mathrm{~g})$ is loaded, and the difference between the peak acceleration of the soil and that of the table is not large, about $0.25 \mathrm{~g}$. When comparing the Fourier spectra of the different height measurement points, the peak of the spectrum at the bottom measurement point is generally smaller, while that at the middle and upper measurement points occurs at $4-7 \mathrm{~Hz}$, with the largest value reaching $0.013\left(\mathrm{~m} / \mathrm{s}^{2}\right) * \mathrm{~s}$. At the last level $(1.55 \mathrm{~g})$, the consistency of the acceleration time course curve of each measurement point becomes worse, the difference between the acceleration of the soil at the bottom and that of the table is not large, but the peak acceleration of the soil at the middle and upper part is smaller than that of the table, and the degree of reduction is obvious. When comparing the Fourier spectra of each measurement point, it was found that the peak Fourier spectra of the soil at the bottom increased significantly with respect to the primary loading, with multiple peaks in the frequency range of $0-20 \mathrm{~Hz}$, while the peak Fourier spectra of the soil in the middle and upper parts of the box showed relatively small increases.

Figure 10 shows the acceleration time curves and their Fourier spectra at each measuring point for peak acceleration of $0.25 \mathrm{~g}$ and $1.55 \mathrm{~g}$ on the table under lateral multipoint excitation. It can be seen that when the peak acceleration of the table is $0.25 \mathrm{~g}$, the peak acceleration of the soil at the bottom and upper measurement points is close to that of the input table, while the peak acceleration of the soil in the middle is slightly smaller than the other measurement points due to the constraints of the pipe. At this time, the soil is in the compaction process, and the overall change in the acceleration time curve is small. The Fourier spectrum amplitude at the bottom shows multiple peaks, which is different from the Fourier spectrum characteristics of the measurement point during the uniform excitation, indicating that the multipoint excitation will have an amplifying effect on the peak of the soil at the bottom. The middle and upper measurement points of 

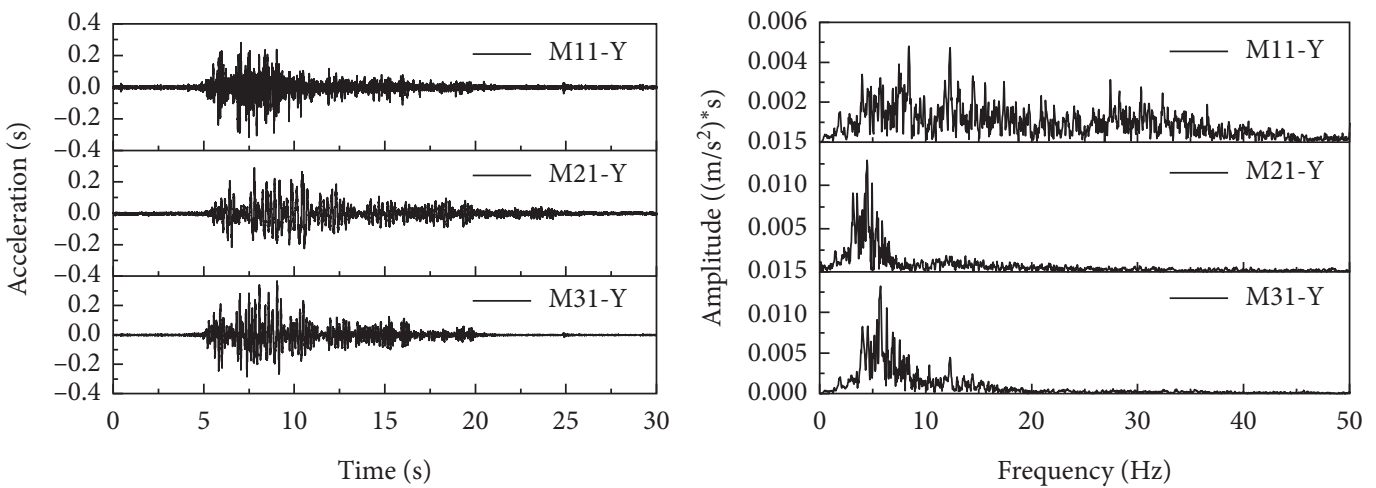

(a)
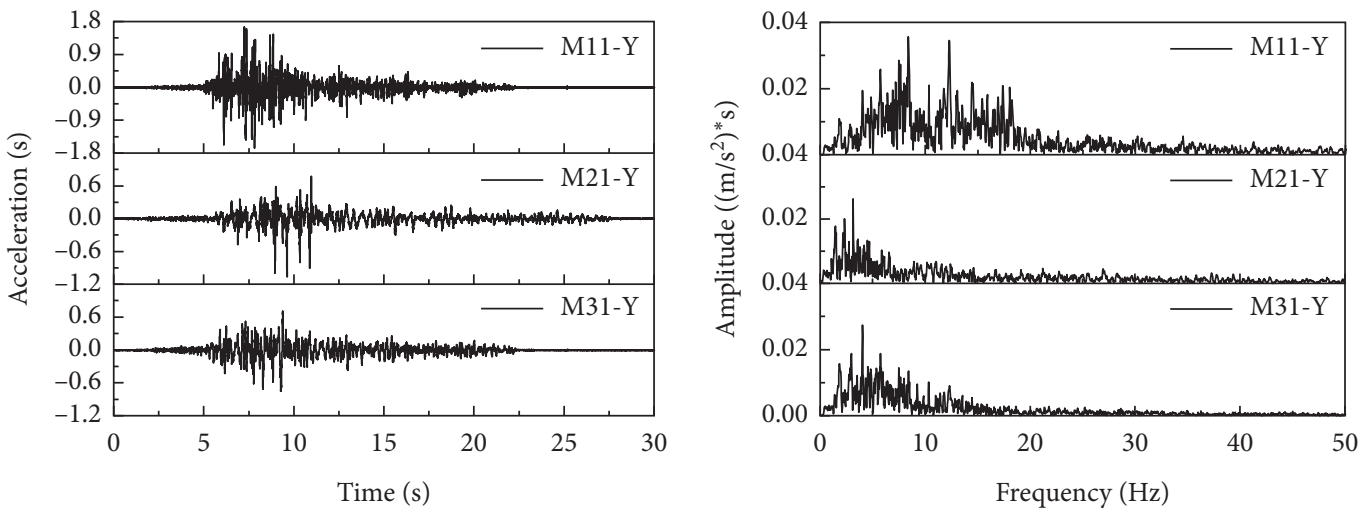

(b)

FIgURE 9: Uniform excitation. (a) $0.25 \mathrm{~g}$. (b) $1.55 \mathrm{~g}$.

the soil also show amplifying effect but the Fourier spectrum waveform does not change much compared to the uniform excitation. When the peak acceleration of the table is $1.55 \mathrm{~g}$, the waveforms of the acceleration time curve of the soil at different heights differ greatly, with the increase of the height of the measurement point; the peak acceleration amplification effect of the soil shows a trend of first weakening and then increasing, in which the peak acceleration of the measurement point M21 near the pipe is the smallest. At this time, the Fourier spectrum of the bottom measurement point still maintains the characteristics of multipeak, but the peak of the spectrum is reduced; the peak of the spectrum of the central and upper measurement points slightly increased compared to the low loading level.

Comparing the acceleration peaks and spectrum peaks of each measurement point during uniform and multipoint excitation, it was found that the consistency of the acceleration time curve of each measuring point gradually decreases with the increase of loading level, and this situation is especially obvious during multipoint excitation. When the peak acceleration of the table is small, the peak Fourier spectrum of the uniform excitation is larger than that of the multipoint excitation. At $1.55 \mathrm{~g}$ multipoint excitation, the peak acceleration of the soil is generally larger than that of the uniform excitation, and the peak
Fourier spectrum of the multipoint excitation also exceeds that of the uniform excitation.

3.5. The Displacement Response of the Soil Layer. The displacement curves with time for different heights of the measurement points within the table acceleration of $0.25 \mathrm{~g}$ and $1.55 \mathrm{~g}$ are presented in Figures 11 and 12. The distance of measurement points D11, D21, and D31 from the bottom of the soil box is $150 \mathrm{~mm}, 360 \mathrm{~mm}$, and $650 \mathrm{~mm}$, respectively.

At a peak table acceleration of $0.25 \mathrm{~g}$, the soil is in the compaction process and shows highly holistic. The soil deformation under uniform and multipoint excitation is small, and the overall difference in its peak displacement is not significant, $9 \mathrm{~mm}$ and $8 \mathrm{~mm}$, respectively. The displacement time curve formed under multipoint excitation is relatively more fluctuating, and the displacement time curve at the bottom measurement point is different from that at the middle and top, and the soil produces residual displacement in the late stage of the loading. When the peak acceleration of the table increases to $1.55 \mathrm{~g}$, the soil exhibits obvious nonlinear characteristics and the displacement time curve waveform is similar to that at low loading levels, but the displacement increases significantly, up to four times that at 

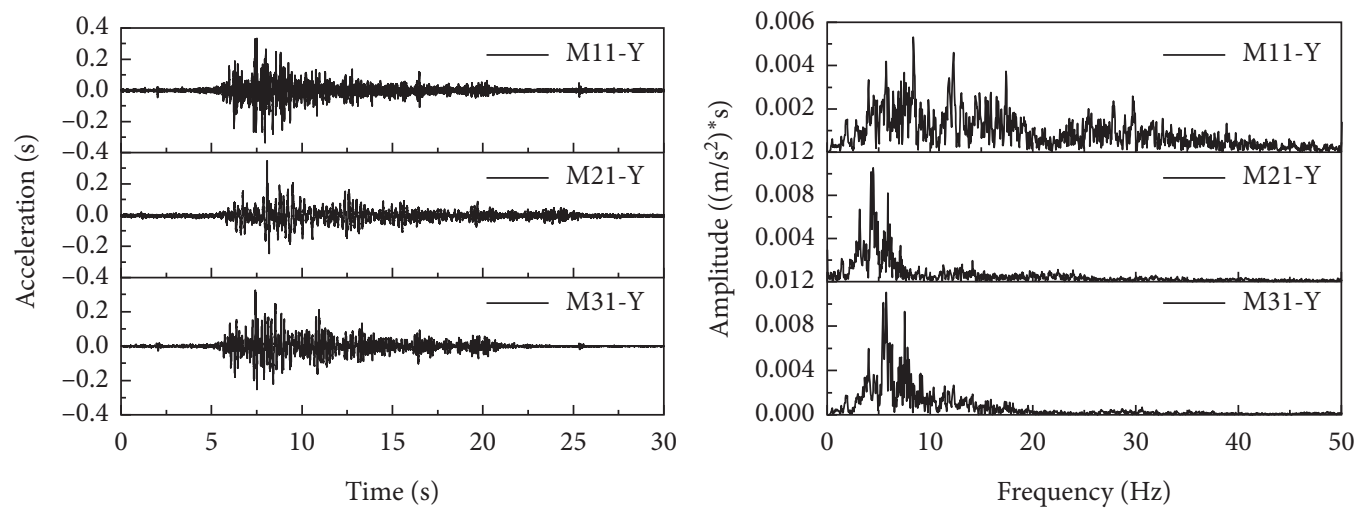

(a)
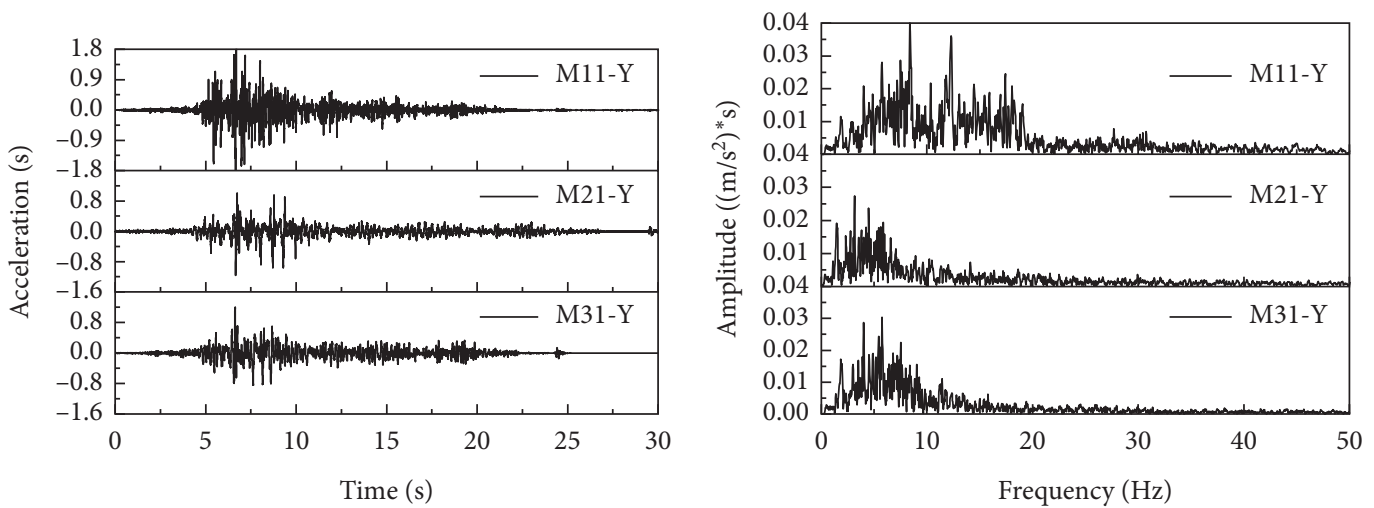

(b)

Figure 10: Multipoint excitation. (a) $0.25 \mathrm{~g}$. (b) $1.55 \mathrm{~g}$.

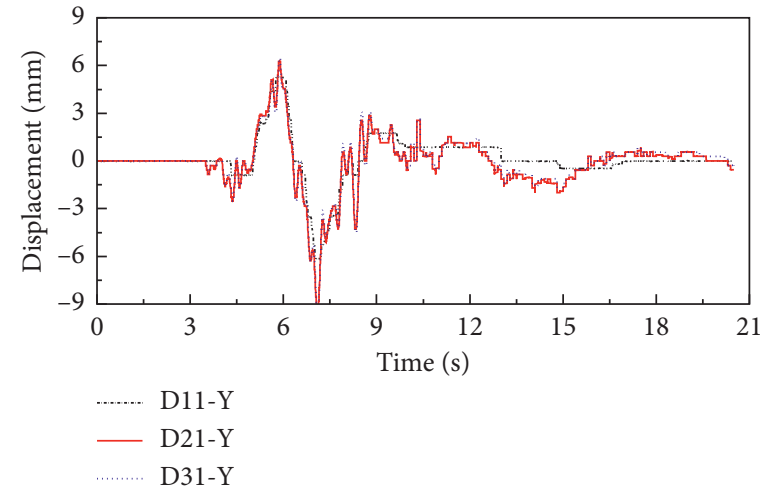

(a)

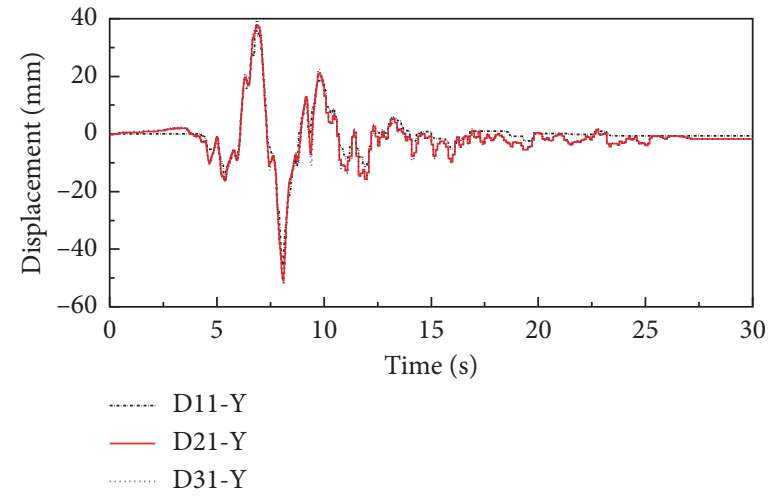

(b)

FIgURe 11: Uniform excitation. (a) $0.25 \mathrm{~g}$. (b) $1.55 \mathrm{~g}$.

$0.25 \mathrm{~g}$. Comparing the displacement curves of different elevation measurement points at the same time, it was found that, at the early stage of loading, the movement direction of each measurement point was the same and the displacement values did not differ greatly, and the shearing effect between soil layers was weak. With the increase of loading time, the displacement of each measurement point in the soil gradually increases, and the inconsistent movement speed of each layer causes the soil to undergo laminar shear, and as the peak acceleration of the table increases, the layer shear effect between each measurement point becomes more obvious. 


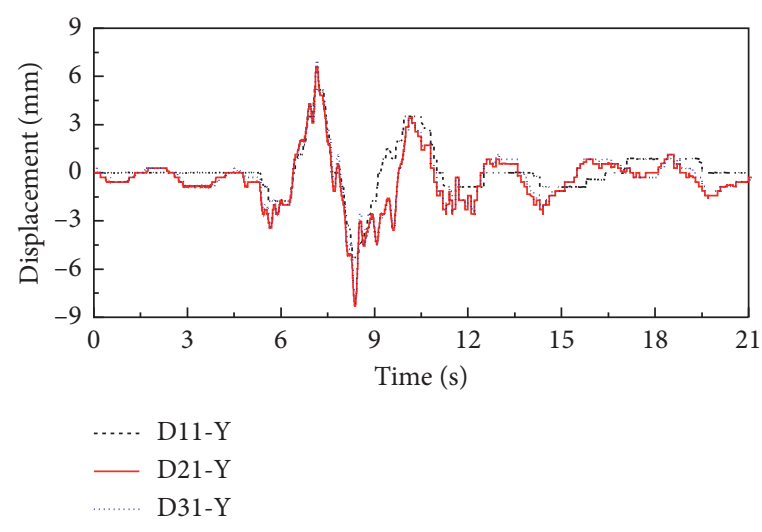

(a)

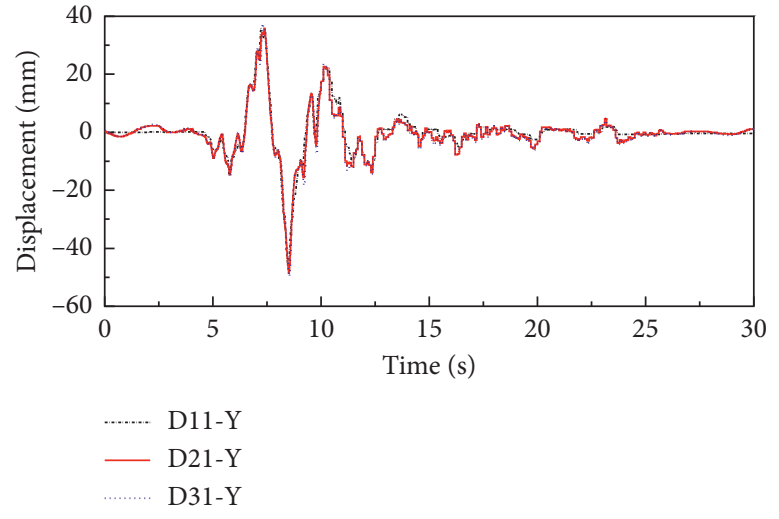

(b)

Figure 12: Multipoint excitation. (a) $0.25 \mathrm{~g}$. (b) $1.55 \mathrm{~g}$.

\section{Conclusion}

In this paper, the seismic response of the soil around buried oil and gas pipelines and their variation characteristics are analyzed through shaking table tests of buried pipelines under lateral uniform and multipoint excitation, and the main conclusions obtained are shown as follows:

(1) The soil exhibits the same trend with increasing loading levels for both lateral uniform and multipoint excitation: the soil undergoes a process of compaction-surface crack development, pronounced nonlinear characteristics, soil damage, with the soil developing faster and causing more serious soil damage during multipoint excitation compared to uniform excitation.

(2) Compared with uniform excitation, the peak acceleration of the pipe is slightly higher than that of the soil at multiple points of excitation, and the difference between the two decreases as the loading level increases, with the peak acceleration of the soil exceeding that of the pipe at a table acceleration of $1.55 \mathrm{~g}$. The peak Fourier spectrum of both the pipe and soil occurs at frequencies of $4-6 \mathrm{~Hz}$ under the loading, and the Fourier spectrum of the pipe is richer than that of the soil.

(3) The acceleration amplification coefficient of the soil tends to decrease and then increase as the elevation of the measurement point increases; the amplification coefficient of the tube circumference shrinks significantly under multipoint excitation. The increase of loading level will cause the waveform consistency of the acceleration response curve of the soil at different elevations worse. At this time, the peak of the Fourier spectrum at multipoint excitation exceeds that of the uniform excitation, which has a greater impact on the seismic response of the soil.

(4) The waveforms of the displacement time curves are similar for both uniform and multipoint excitation, and the acceleration time curves at each measurement point do not vary significantly with elevation; under seismic excitation, the shear effect between the soil layers becomes more obvious with the increase of the peak acceleration at the table. Compared with uniform excitation, the displacement time curves of multipoint excitation show smaller fluctuations, but the overall effect of the excitation method on the soil displacement is not significant [19].

\section{Data Availability}

The data used to support the findings of this study are available from the corresponding author upon request.

\section{Conflicts of Interest}

The authors declare that they have no conflicts of interest.

\section{Acknowledgments}

The authors gratefully acknowledge the National Natural Science Foundation of China (grant no. 51808446) (Research on Disaster Mechanism and Seismic Performance of Long Distance Oil and Gas Pipelines under Multi-Dimensional and Multi-Support Earthquake Excitation) and Key Research and Development Program of Shaanxi (grant no. 2019SF-266) (Research on Stress Detection and Safe Operation Monitoring System for Oil and Gas Pipelines in Service).

\section{References}

[1] M. Castiglia, T. Fierro, and F. Santucci de Magistris, "Pipeline performances under earthquake-induced soil liquefaction: state of the art on real observations, model tests, and numerical simulations," Shock and Vibration, vol. 2020, Article ID 8874200, 20 pages, 2020.

[2] P. Burkov, C. Wu, V. Burkov, and S. Burkova, "FEM analysis of soil-pipe interaction," AIP Conference Proceedings, vol. 1863, no. 1, pp. 1-4, 2017.

[3] A. Vishwajit and S. R. Satish Kumar, "Seismic soil-structure interaction: a sate-of -the-art review," Structure, vol. 16, pp. 317-326, 2018. 
[4] A. Haydar and S. Bilge, "A comparative study on linear and nonlinear site response analysis," Environmental Geography, vol. 50, no. 8, pp. 1193-1200, 2006.

[5] A. Haydar and S. Bilge, "Effect of nonlinearity on site response and ground motion due to earthquake excitation," Bulletin of Engineering Geology and the Environment, vol. 69, pp. 287293, 2010.

[6] J. Yang and X. R. Yan, "Factors affecting site response to multi-directional earthquake loading," Engineering Geology, vol. 107, no. 3-4, pp. 77-87, 2009.

[7] D. Angshunan and C. Pradipta, "Influence of motion energy and soil characteristic on seismic ground response of layered soil," International Journal of Civil Engineering, vol. 18, no. 7, pp. 763-782, 2020.

[8] R. Alireza, K. Mohanmmadreza, and H. Mir Raouf, "Numerical investigation of closed-form solution for seismic design of a circular tunnel lining (by quasi-static method)," Civil Engineering Journal, vol. 4, no. 1, pp. 239-257, 2018.

[9] T. R. Rashidov, T. Yuldashev, and D. A. Bekmirzaev, "Seismodynamics of underground pipelines with arbitrary direction of seismic loading," Soil Mechanics and Foundation Engineering, vol. 55, no. 4, pp. 243-248, 2018.

[10] H. Delong, T. Aiping, and W. Zhongyue, "Analysis of pipesoil interactions using goodman contact element under seismic action," Soil Dynamics and Earthquake Engineering, vol. 139, Article ID 106290, 2020.

[11] M. Subramanian, G. Pearce, O. K. Guldu et al., "Multi-point shaking table test of a long tunnel subject to non-uniform seismic loadings," Bulletin of Earthquake Engineering, vol. 16, no. 2, pp. 1041-1059, 2018.

[12] Y. Yong, Y. Haitao, and L. Chong, "Multi-point shaking table test for long tunnels subject to non-uniform seismic loadingspart I: theory and validation," Soil Dynamics and Earthquake Engineering, vol. 108, pp. 177-186, 2018.

[13] Z. Ouyang, J. Cui, R. Luo, and P. Li, "Shaking table test of seismic response of immersed tunnels under the influence of multiple factors," Shock and Vibration, vol. 2020, Article ID 8858486, 17 pages, 2020.

[14] H. Junyan, M. Hesham Ei Naggarb, H. Benwei et al., "Nonlinear soil response under non-uniform seismic excitation form multi-point shaking table teats," Soil Dynamics and Earthquake Engineering, vol. 139, Article ID 106342, 2020.

[15] K. Yan, J. Zhang, Z. Wang, W. Liao, and Z. Wu, "Seismic responses of deep buried pipeline under non-uniform excitations from large scale shaking table test," Soil Dynamics and Earthquake Engineering, vol. 113, pp. 180-192, 2018.

[16] T. George, J. Virieux, and R. Madariaga, "Seismic wave synthesis by Gaussian beam summation: a comparison with finite difference," Geophysics, vol. 52, no. 8, pp. 1065-1073, 2012.

[17] G. Fatih, S. Murat, and C. Erkan, "Small shaking table testing and numerical analysis of free-field site response and soilstructure oscillation under seismic loading," Bulletin of Engineering Geology and the Environment, vol. 79, no. 6, pp. 2949-2969, 2020.

[18] P. C. Li and H. Wang, "A novel strategy for the crossarm length optimization of PSSCs based on multi-dimensional global optimization algorithms," Engineering Structures, vol. 238, Article ID 112238, 2021.

[19] X. Li, X. Wang, L. Li et al., "Design and performance test of 3D laminar shear container for shaking table," Rock and Soil Mechanics, vol. 38, no. 5, pp. 1524-1532, 2017. 